\title{
Research on e-commerce management objects under Information Technology
}

\author{
Wang Jiantao ${ }^{1}$ \\ ${ }^{1}$ E-commerec College of Business Xian International University, Xian Shanxi China, 710077
}

Keywords: information technology; e-commerce; management object; explore

\begin{abstract}
E-commerce is the modern development of business trip, especially with the deepening of economic globalization and Zhan, e-commerce has become one of the primary choice of trading methods. And the development of electronic commerce, cannot do without the support of information technology, it can be said that e-commerce is the development on the base of computer and derivative development, as long as the constant promotion of information technology, to promote the development of electronic commerce. This article aims at the management object of e-commerce under the information technology.
\end{abstract}

\section{Introduction}

The use of computer technology in e-commerce products reasonably, effectively control the production process of computer products, sales of electronic business can more effectively promote product sales, mutual cooperation between the two, in the era of Internet, e-commerce will be rising type development. Especially Internet technology, Web technology, electronic payment technology, logistics and distribution technology, etc., have been widely used in e-commerce business development. This paper explores the management objects of e-commerce under information technology.

Information technology literally, we are not difficult to understand, it is through the use of modern technology and multimedia, words, numbers, pictures and sound together, then, mathematical and management work together, in order to realize the control of the internet. The emergence of information technology breaks the limitations of time and space, and has become a widely used technology in various fields of our country[1].

E-commerce is a business activity based on information technology, including electronic information management, such as production process, distribution process, circulation link, exchange link, consumption link and so on. In these areas, there is no doubt that information technology should be used as a support.

In the age of computers, everything in our life is bound to be separated from the computer. In the Internet era, we solve all sorts of troubles in our life and form a platform for online transactions. In the life and in practice has the better development, the implementation related, the electronic commerce and the computer information technology joint application has the better rise space[2].

There is a close relationship between information technology and e-commerce, and the two are complementary and mutually reinforcing. Electronic commerce is the use of Internet technology, business exchanges and cooperation with the enterprise information needs to form a relatively complete object, then the standardization and systematization of the management by object. The enterprise can get all kinds of information resources needed by the enterprise through the e-commerce platform of enterprises can also be through whenever and wherever possible, high efficient utilization of information technology to optimize management of e-commerce platform, and promote the development of the enterprise long-term stable.

\section{The content of e-commerce activities}

The electronic commerce activities mainly from three aspects, namely e-commerce activities between e-commerce activities between enterprises and e-commerce activities, enterprises and government, enterprises and consumers. 
With the further development of economic globalization, e-commerce activities between enterprises and enterprises are becoming more frequent. Through the efficient use of e-commerce platform, it provides more opportunities for the exchange and cooperation between enterprises and enterprises, and promotes the development of enterprises. In general, e-commerce activities between enterprises and enterprises mainly include enterprises to achieve orders, payments and the development of electronic invoices and other acts through the internet. That is what we often refer to as the B-T0-B electronic business model. The emergence of this model is very important for promoting the growth of China's national economy. It can be said that the emergence of electronic commerce, between enterprises and the transaction can be completed in a more rapid speed, so compared with the traditional business model, there is no doubt that reduces the number of complicated transaction procedures, make the office efficiency of enterprises more efficient. It is because the electronic commerce has such advantages, so many enterprises in China are beginning to use electronic commerce, enterprises through the effective development of e-commerce, which can improve the enterprise's internal management efficiency, also can make the enterprise can be more accurate on the overseas market for positioning analysis, the enterprises to expand market share to win more customers[3].

With the extensive application of e-commerce, government departments have begun to use e-commerce to complete government procurement, government information dissemination, data utilization, and so on. Here are some examples to illustrate. For example, the Chinese government can issue a list of items to be purchased through Internet. When the information content is released, which can meet the needs of government procurement of China's large enterprises can respond to the government through the electronic form, the Chinese government after the price list is provided by each enterprise and enterprise qualification, you can determine the required cooperation enterprise. This is of great help to the efficiency of government offices.

At this point, every consumer's feelings are particularly obvious, and even to say that our lives today can not be separated from e-commerce. For consumers, when they want to buy goods, you can no longer choose to go to supermarkets or stores, but through Taobao, overseas Amoy and other e-commerce shopping sites for the purchase of goods required. This purchase is for consumers to save time, but also provide more choices for consumers to buy goods, they can compare the price in the purchase of goods, and then choose the most high quality and inexpensive goods. It also provides a good guarantee for seven days of no reason to return it, which reduces a lot of trouble compared to buying goods in supermarkets and shopping malls.

\section{Analysis of e-commerce management objects under Information Technology}

For the management objects of e-commerce under the information technology, financial management is one of the most beneficial aspects. The application of information technology in the financial management work, can make financial management more open and transparent, to ensure the authenticity of financial information, but also conducive to the realization of information and system of financial management, financial work to reduce the chance of error to the maximum extent possible and financial fraud. At the same time, through the application of e-commerce, can help enterprises to scientific analysis and control of finance. It is said that the information technology can make the data management of e-commerce is to find out more quickly, enterprises can be judged according to the financial situation of the real effective financial data on their own, after the enterprise in the understanding of their true financial condition, can be combined with the current market environment forecast, formulate scientific and effective marketing plan. Can also adjust the current development trend of enterprises, help enterprises to find a more suitable for the road of development, improve the profitability of enterprises. In simple terms, is to develop e-commerce business can be the financial information analysis system, and then the allocation of cost accounting, investment direction, resources for their own conduct more in-depth understanding and control, in a comprehensive grasp, then formulate the development strategy of the enterprise, can save more cost for the enterprise, which has an important influence to help enterprises maximize profits. At the same time, information technology is also conducive to the supervision of 
the enterprise financial management and control, the supervision department of the enterprise can be based on information technology, to understand the real and effective financial information for the enterprise, the foundation to promote the development of enterprise information and lay a $\operatorname{good}[4]$.

The management object of e-commerce under the information technology also includes file management. It can be said that archives management has gained great development with the help of information technology. In the traditional file management work, mainly depends on the manpower to carry on the operation, but the quantity of the archives is close, the type is quite diverse. The workload is very large, they should not only archives classification place, but also for editing and Paihao for each file, so it is convenient to find. But even if you do, it will take a lot of time to find the file you need in so many files. With the development of information technology, archives realize the information management in the context of e-commerce. Its implementation not only reduces the workload of the staff, but also helps those who need to find the files they need more quickly. For example, managers can at any time the data in the file, such as age, gender, address, characteristics, whether or not criminal records and other data are information management, stored in the e-commerce platform. When you need to find files, you only need to enter the relevant data content, you can quickly find the data, saving time and effort. At the same time these important data files such as sex ratio, age structure and other information can also be directly submitted to the statistics after the completion of the required government departments can take these data analysis as a basis for government departments to formulate relevant policies in all sectors of society, of course, can also be required to file information through the relevant software the application of search. With the realization of the archives management informatization in our country, the archives management department should put forward higher level requirements for itself, and constantly improve the work level of the management staff. In the background of the development of today's information, there is no doubt that the traditional file management mode can not keep up the pace of development of the times, is in the process of phasing out, so in order to meet the needs of the development of information technology, archives management departments should be engaged in the work of archives management personnel training related to computer technology, such as how to e business information platform for file management, how to efficiently release information through the information platform and so on, this is the hope of saving human capital in the largest extent, fewer people are more management of archives, and archives data entry, data storage, data archives archives information search. Informatization of the whole process of archival data information retrieval. In addition, the archives management department should keep pace with the development of the times, vigorously apply e-commerce information management, and introduce the latest file management software to improve the informatization level of the archives management[5].

For e-commerce, its transactions and payments are done through the virtual network. In order to ensure that the interests of the main subject is not damaged, as a government department, the currency must be strengthened supervision. In e-commerce activities, the government should play the role of "electronic police", to prevent market e-commerce transactions in the harsh competition, false trading behavior, maintain a good e-commerce market fair, build a good environment for e-commerce market. So when the government once found illegal or fraud and other bad behavior in e-commerce activities, we must crack down without mercy. Of course, because of the development of information technology, it can make a full range tracking of the whole process of e-commerce communication, that is to say, every transaction on my electronic can be found intact and accurate. Government departments and the public security departments can, according to the actual situation, conduct a comprehensive grasp of the e-commerce communication process and do a good job of monitoring. In addition, for the government, through e-commerce can help the government to achieve the purchase of goods in a large centralized purchase, for the government procurement of goods to save certain costs. Every year the government needs some purchases, the government procurement list of items can be set out and purchasing budget publicity through the official website of the government, and to meet the needs of the government of each big enterprise can through the Internet in the form of e-commerce bidding. The government can choose the best enterprise 
according to the price, quality and the qualification of the enterprise. Not only does this provide the government with efficiency, it also helps the government to save costs. The most important point is that through information disclosure initiatives, to the greatest extent to avoid corrupt practices, and enhance the credibility of the government in the masses. At present, with the rise of new media, all kinds of false information and reliable public opinion wanton spread on the Internet, especially in recent years, official corruption, is a serious impact of our party and the government's good image in people's minds. In order to change this situation and avoid the spread of false statements, the government supervision departments can use information technology to effectively monitor network information. Of course, for the government, we can also hear more people's voices through the Internet, so that the government is making policy and will be based on the actual needs of the people to the greatest extent to meet. It can be said that the electronic commerce under the current information technology has become one of the effective bridges between our party and the government and the masses[6].

\section{Conclusion}

To sum up, we should be able to clearly and accurately recognize that today's era is the electronic information age, we really realized "the scholar does not go out, everyone else". Computers and the Internet have come into our study, work and life, making great changes in the way we spend. Originally, for the enterprise, if we want to cooperate with another enterprise, we have to go through a lot of complicated procedures, and the two sides can finally determine the intention of cooperation. It would be more troublesome to cooperate overseas. A successful cooperative project would take less than a few months, and it would cost more than a year or even a few years. The cost would be very high. However, with the emergence of e-commerce trading platform, all this has become "So easy", both improved work efficiency, but also save costs. Thus, e-commerce management under the information technology has become the main body of today's economic activities. So in the current context, in order to promote the development of economy, we must analyze and research the management of e-commerce activities and information technology under the electronic commerce management object, make the development more development strategy to promote the better optimization.

\section{References}

[1] Montana J C. The Law And Records -- Rarely The Twain Shall Meet[J]. Information Management Journal, 2001, :35(:2).

[2] Hang L, Lei M. Definition of Managed Objects for Fault Management of Satellite Network[C]// International Forum on Information Technology and Applications. Ieee, 2009:107-110.

[3] Hughes J, Lang K R, Clemons E, Et Al. A Unified Interdisciplinary Theory Of Open Source Culture And Entertainment[J]. Ssrn Electronic Journal, 2007.

[4] Quilty S M. Study Results On Knowledge Requirements For Entry-Level Airport Operations And Management Personnel[J]. Journal of Air Transportation, 2005.

[5] Yi N. The Object Of Electronic Commerce Management Under Information Technology[J]. Electronic Test, 2014.

[6] Albano G L, Germano F, Lovo S. On Some Collusive And Signaling Equilibria In Ascending Auctions For Multiple Objects[J]. Ssrn Electronic Journal, 2002. 